\title{
Multi-Joint Dynamics and the Development of Movement Control
}

\author{
E. Otten \\ Institute of Human Movement Sciences, Groningen, the Netherlands
}

\begin{abstract}
The movement control of articulated limbs in humans has been explained in terms of equilibrium points and moving equilibrium points or virtual trajectories. One hypothesis is that the nervous system controls multi-segment limbs by simply planning in terms of these equilibrium points and trajectories. The present paper describes a planar computer simulation of an articulated three-segment limb, controlled by pairs of muscles. The shape of the virtual trajectory is analyzed when the limb is required to make fast movements with endpoint movements along a straight line with bell-shaped velocity profiles. Apparently, the faster the movement, the more the virtual trajectory deviates from the real trajectory and becomes up to eight times longer. The complexity of the shape of the virtual trajectories and its length in these fast movements makes it unlikely that the nervous system plans using these trajectories. It seems simpler to set up the required bursts of muscle activation, coupled in the nervous system to the direction of movement, the speed, and the place in workspace. Finally, it is argued that the two types of explanation do not contradict each other: when a relation is established in the nervous system between muscle activation and movements, equilibrium points and virtual trajectories are necessarily part of that relation.
\end{abstract}

Reprint requests to: E. Otten, Institute of Human Movement Sciences, Groningen, The Netherlands e-mail: e.otten@med.rug.nl

\section{KEYWORDS}

limb control simulation, equilibrium point hypothesis

\section{INTRODUCTION}

Several theories have been put forward on the control of limbs. One of them is known as the "equilibrium point hypothesis" (Bizzi et al., 1992). This hypothesis states that a limb is controlled by setting up muscle activations that lead to a certain equilibrium position of the limb. In this way, the nervous system simply has to set up a series of equilibrium positions to generate various movements. This hypothesis is based on a set of experiments with a frog's hind limb (Giszter et al., 1993). The spinal cord was stimulated and the resulting limb position was recorded. During the stimulation, the limb was pulled away at its endpoint, after which the force needed to pull it away was recorded. In this way, a vector field was found with only one equilibrium point. This finding was used to make the argument that the nervous system actually controls the limb, using these equilibrium points. It should be pointed out, however, that the equilibrium point hypothesis is based on two assumptions:

1. A limb with articulated segments, of which the joints are spanned by skeletal muscles, always has a unique equilibrium endpoint position for any set of muscle activations.

2. The nervous system activates muscles of a limb in sets that belong to equilibrium end- 
point positions, so that the limb moves in the direction of these endpoint positions.

Obviously, the first statement simply tells us something about the tendency of mechanical chain systems with variable elastic elements (the muscles) to have single equilibrium points for constant properties of the elastic elements. One can create such systems with more than one equilibrium point, but according to the experiments, the frog is not one of them. However, the second part of the equilibrium point hypothesis is more interesting to study from a control point of view. In order to do so, I have formulated a simulation of a limb, consisting of three segments, very much like the frog's hind limb.

\section{THE MODEL}

The model consists of four segments, of which one segment represents the body of the organism, while three segments are linked in a chain. The system is kept in a single plane, while the mechanics is formulated according to Otten (2003). The muscles and their activation are formulated as simple as possible-as pairs of muscles around each of the three joints. The cocontraction is kept constant for all levels of activation at a level of $2.5,1.25$, and $0.625 \mathrm{Nm}$, respectively, for the joints from proximal to distal. A constant amount of damping is added to the joints of $0.7071,0.3536$, and $0.1768 \mathrm{Nm} /(\mathrm{rad} / \mathrm{sec})$, respectively. The control of the model is performed by selecting angles of the joints at which the net torque is zero. The angles at which the muscles have reached their minimal active length are respectively -1.8850 and 1.8850 radians for the most proximal joint, -3.4558 and 0.3142 radians for the middle joint, and -0.3142 and 3.4558 radians for the most distal joint. Therefore, the range of each joint is 3.77 radians or slightly over half a circle. Each limb segments has a length of 0.5 meter. It should be pointed out that the model can be scaled under the restriction of dynamic similarity and still produce the same results (Alexander and Jayes, 1983). In order to scale the model, the lengths of the segments can be scaled by a factor of $\mathrm{S}$, the simulation time by the square root of $S$, the masses by the third power of $S$, the stiffnesses by the fourth power of $S$, and the damping by the 4.5 power of $S$. The resulting accelerations of the model scale by a factor of 1 , the velocities by the square root of $S$, and the amplitudes of motion by $\mathrm{S}$. The joint angles scale by a factor of 1 . These scaling properties are important for studying the development of movement control because the scaling is not uniform. This is relevant in view of the time-courses of control and the morphological scaling of the growing organism.

The first simulation consists of a constant activation of the muscles at the joint, pulling the endpoint away and calculating the necessary force for a prescribed endpoint position, which produces a force vector field, shown in Fig. 1.

Since the movements of the endpoint of the limb follows the arrows of the vector field, with some extra movements due to inertia, it follows that if the limb is not situated in an equilibrium position, it will move there over a non-straight trajectory. Indeed, when such a simulation is performed, the motion is not straight. Figure 2 illustrates this against the background of the potential field, which is calculated from the accumulated spring energy in the muscles.

This already forms a challenge for the equilibrium point hypothesis. When the nervous system moves the limb by setting up a new equilibrium point by selecting an appropriate activation level of the limb muscles, the endpoint of the limb moves along a curved path, which is not very practical for planning and executing movements of the endpoint in workspace. 


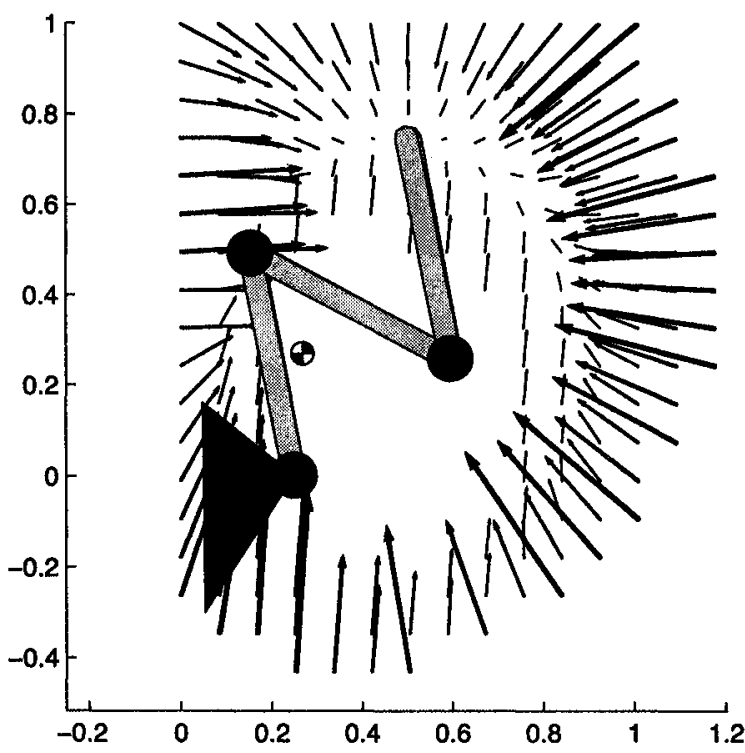

Fig. 1: Force vector field of articulated limb at one combination of muscle activation. The arrows indicate the forces and are scaled in length and width proportional to the force magnitude

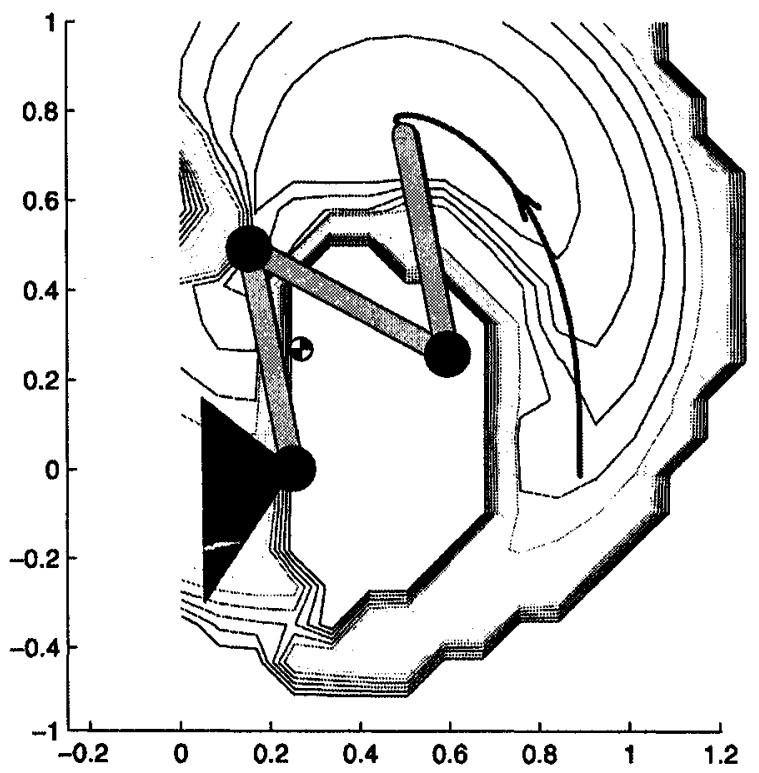

Fig. 2: Movement of an articulate limb when a static equilibrium point is used with contour lines of constant potential energy. Note the curved shape of the endpoint trajectory 


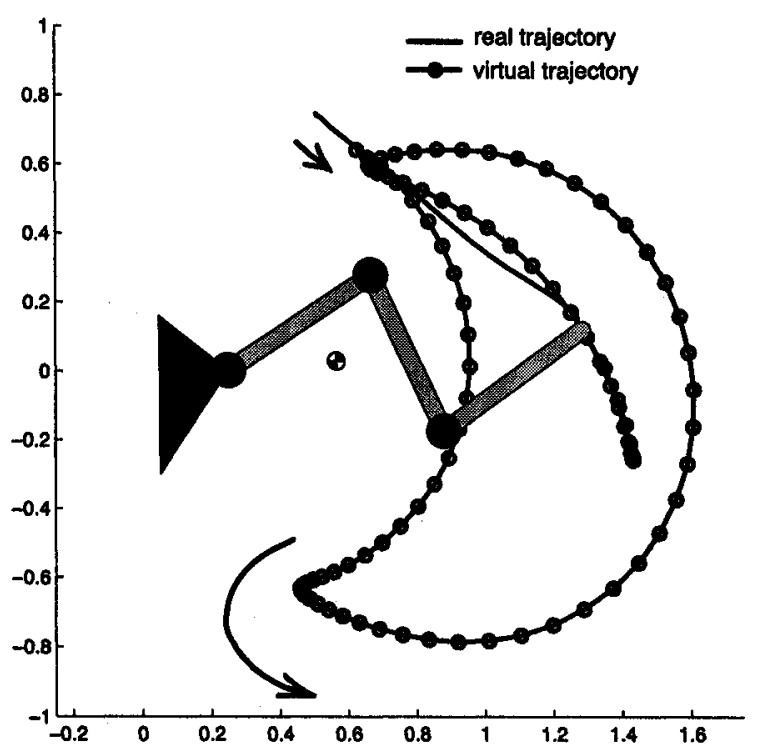

Fig. 3: Virtual and real trajectory of a fast movement of a simulated articulated limb. Note the complex shape of the virtual trajectory for this simple straight line endpoint movement with bell-shaped velocity profile. The complex shaped virtual trajectory is due to the fact that the real limb needs to be accelerated and decelerated while its endpoint remains on a straight path.

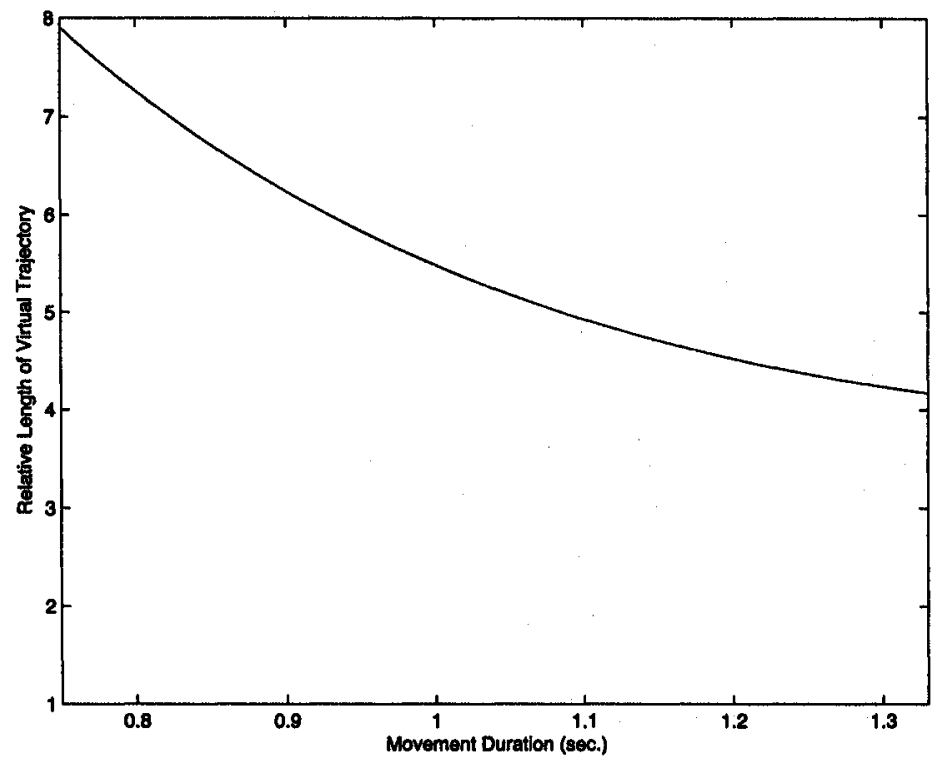

Fig. 4: The virtual trajectory length of a simulated articulated limb becomes longer with decreasing movement time and increasing endpoint velocity. 
Now, one could argue that the nervous system is not using static equilibrium points but rather virtual trajectories to drive the endpoint of the limb (Latash \& Gottlieb, 1991). This looks like an attractive solution to the above-mentioned problem, but as I will show here, this view has its problems for fast limb movements.

The model was set up to move the endpoint over a straight line. The model has to perform the movement in $0.71 \mathrm{sec}$. over a distance of 1 meter. This was done by using a multidimensional search for six activation levels over time of the three muscle pairs at the joints. The six levels were interpolated by splines over time to obtain smooth changes in muscle activation. After the search was completed, the endpoint did indeed move over a straight line with very small tolerances. The trajectory was required to have a bell-shaped velocity profile, implying a sigmoid position profile. Figure 3 shows the trajectory and the virtual trajectory that belongs to the movement as well.

As can be seen, the virtual trajectory is very complex in shape and has several turning points, due to the high speed of the movement. The slower the movement, the more the virtual trajectory resembles the real trajectory of the endpoint.

Several authors, amongst them Latash (1998), claim that such virtual trajectories are used for planning movements. The present simple model shows that fast limb movements are not likely planned with virtual trajectories because these trajectories are much more complex than the activation patterns of the muscles. ('Complex' is to be expressed here in terms of the number of necessary parameters to describe them properly as function of time). Moreover, the shape of the virtual trajectory changes at different movement velocities.

In order to show the relation between the speed of execution of the movement and the difference between the virtual trajectory and the real trajectory, muscle activations were optimized for the same straight movement performed at different velocities. The criterion for optimization was to minimize the difference of the endpoint trajectory with a straight line trajectory having a bell-shaped velocity profile. The ratio of the length of the virtual trajectory and the real trajectory is plotted as a function of the average velocity of the movement and shown in Fig. 4. As can be seen, at the highest velocity the virtual trajectory is eight times longer than the real trajectory. Such velocities can easily be attained by warm-blooded organisms like humans. It should be noted that this result is acquired for the movement as presented in the figures. Other trajectories would yield other results, so it is presented here only for the purpose of an illustration. The analysis of an extensive catalogue of movements is beyond the present paper.

Another interesting phenomenon is the change in the activation pattern of the muscle groups at different velocities. Not only the amplitudes but also the relative timing of the muscle bursts change, showing that a simple linear amplitude and time scaling is insufficient to perform the movements at different velocities.

\section{THE CONTROL PROBLEM}

Publications like the one produced by Won and Hogan (1995) illustrate the problem of arm control in humans. The authors constrained voluntary human hand movements and found restoring forces in the direction of the unconstrained trajectories. Won and Hogan claim that the results are "showing that a controlled equilibrium point may be used for planning and coordinating multijoint movements". The authors reason from the mechanical properties of the controlled limb to the control itself. However, the simulation that I present here, modeling an articulated limb, has the same property of restoring forces in the direction of unconstrained trajectories. Yet, in building and executing the model, no assumptions were made on planning or control, only on the mechanical properties and the 
required endpoint movement.

The foregoing then leads to the following two possibilities:

1. The nervous system plans movements in terms of static or moving limb endpoint-equilibrium positions.

2. The nervous system plans movements by looking up adequate muscle activations to move a limb from one point to the other with certain duration.

Let us look at the requirements for each of these possibilities.

Both theories require a reliable muscle-boneconnective tissue system that always has unique endpoint positions for every combination of muscle activations. Both theories require a learned representation of motor tasks. The first theory describes this representation as a prescribed endpoint or virtual trajectory, the second one as a complex transfer relation of muscle activations to limb movements. So, the parts where the theories differ are those referring to the nervous system. To find out what goes on in the nervous system, we can use data from the movements and forces and from recordings of neural activity.

Data on movements and forces are abundant and are interpreted by the observers in the direction of the neural process. Because there is sufficient latitude in these observations, they cannot be used to rule out one of the theories. However, recordings from the nervous system have also rendered important data.

Moran and Schwarz (1999) found cortical neurons in monkeys that have firing components for speed and direction independently. That is an important addition to the observation reported by Georgopoulos et al. (1982) of direction dependent firing patterns. Together these observations suggest that in the cortex, there is information in terms of firing patterns on direction, position, and speed in the workspace of a limb. That certainly would favor the equilibrium point hypothesis. If the information in the cortex is so directly linked with the coordinate system of the workspace, then why not use it for planning?

Caminiti et al. (1991) recorded the activity of premotor and motor cortex neurons and found comparable direction-dependent firing patterns. The authors interpreted their findings in terms of neuronal representation of the task in workspace, without referring once to the equilibrium point hypothesis. Later on Scott at al. (1997) found that such workspace-related firing patterns change with changing limb orientations. That makes sense because even if you have information in workspace coordinates, you can not do much with it if you do not use information in joint-space coordinates.

Let us carefully consider the arguments. The two theories do not differ in their statements on what is exactly controlled. Both claim that ultimately it is the physical limb. The two theories differ only in the abstract concept of representation: in the first theory, it is the virtual trajectory; in the second theory, it is the transfer function. Because for both representations, some neurons in the network carrying the representation may be firing with respect to movement direction, this observation does not exclude either one of the theories.

When we consider the matter purely from a viewpoint of economy and simplicity, the virtual trajectory hypothesis held a promise in this respect. This was true only for the simulations performed by Flash and Hogan (1985) with considerable arm stiffness. In their simulations, the virtual trajectory was not very much different from the real endpoint trajectory. In the present model, the virtual trajectories are much more complex, so that the virtual trajectory hypothesis looses its advantage. In fact, the low stiffnesses of the present model directly follow from the low level of cocontraction used. This is in agreement with findings of Bennet et al. (1992) during voluntary human arm movements, in which the stiffness drops during the motion. Again, we have no indication 
which of the two theories has the advantage in terms of a simple representation.

\section{AN INTEGRATION}

When we go back to the present simulation, it is obvious that when we optimize a simple model of an articulated limb to perform a straight-line endpoint trajectory, the required muscle activations are complex and depend on the velocity used. Planning in a virtual trajectory does not provide an advantage over planning in terms of transfer functions of muscle activation to workspace. If we forget the abstract notions of transfer functions and virtual trajectories for a while and consider the process of development and learning, it is clear that without any supervision, the neural system simply has to find a way to move the limb in an effective way. Development and learning differ from each other in the sense that during development completely new strategies have to emerge, whereas learning strategies that are already present can be combined or rescaled. In both cases, however, information has to be accumulated on the dynamic properties of muscles and on those of the limb segments.

Additionally, information about the whole system has to be acquired, while the endpoint moves in various parts of the workspace. If we have learned anything from neural network simulations, it is that the nervous system is very good in finding complex transfer functions, so it should be possible to find them for limb motion. In doing so, the nervous system also finds representa-tions for the virtual trajectories because they are the result of the time-varying activation patterns at different directions in workspace, independent of arm posture. Those representations are emerging from the primary goal-controlling the limb fast and effectively. When we consider the matter in this way, there is no reason to select one theory over another. The theories do not exclude each other, as long control is the purpose and the representations only epi-phenomena.

The statement that the two theories do not exclude each other invites further research into the properties of limb conirol. What are the limitations of the neural control of limb movements? When we look carefully at human limb movements, we see that they are not perfect. In the 'good enough' approach of the learning process, we see deviations from straight paths and errors in fast pointing tasks or when under the load of some tool. In those errors, part of the way the nervous system has stored the representation of the limb and its task is hidden. It would be worthwhile to study these deviations during development and in situations in which control is limited, due to some developmental pathology. This approach would give us more insight in the kind of mappings that are used from movement planning to muscle activation and from there to endpoint movements.

\section{DISCUSSION}

A number of discussions in the literature on the equilibrium point and trajectory hypothesis (for instance by Gomi \& Kawato, 1996), stating that producing virtual trajectories is at least as complex as creating the dynamics itself, started to undermine this elegant hypothesis. The fact that the real endpoint trajectories are straight, even under perturbed visual feedback (Wolpert et al. 1995 ) is quite a strong indication that equilibrium planning is not used, and that view is clearly corroborated by the present simulation. By the same token, under the condition of an unexpected disappearance of an external load, subjects do not reach the endposition of their hand (Hinder and Milner, 2003), suggesting that this control is the result of an internal dynamics model rather than equilibrium trajectory planning. It should be stressed here, that although equilibrium planning might not be used, equilibrium points and 
trajectories are still part of the mechanics of the controlled limb.

\section{REFERENCES}

Aicardi J, Bax M. 1992. Cerebral palsy. In: Aicardi J, ed, Diseases of the Nervous System in Childhood. (Clinics in Developmental Medicine, Nos. 115118). London, UK: MacKeith Press, Oxford Blackwell Scientific Publications; 330-374

Altman J, Bayer SA. 1984. The development of the rat spinal cord. Adv Anat Embryol Cell Biol 85: 1164.

Altman J, Bayer SA. 1996. Development of the Cerebellar System. Boca Raton-New YorkLondon-Tokyo: CRC Press; 1-783.

Altman J, Sudarshan K. 1975. Postnatal development of locomotion in the laboratory rat. Anim Behav 23: 896-920.

Brodal P. 1992. The cerebellum. In: Brodal P, ed, The Central Nervous System, Structure and Function. New York, NY, USA: Oxford University Press; 262-282.

Cazalets J-R, Borde M, Clarac. 1995. Localization of the central pattern generator for hindlimb locomotion in newborn rat. J Neurosci 15: 4943-4951.

Cazalets J-R. 2001. Development of the neural correlates of locomotion in rats. In: Kalverboer AF, Gramsbergen $A$, eds, Handbook of Brain and Behaviour in Human Development. Dordrecht, The Netherlands: Kluwer; 447-466.

Chatterjee S. 1982. Phylogeny and classification of theco-dontian reptiles. Nature 295: 317-320.

Clancy B, Darlington RB, Finlay BL. 2001. Translating developmental time across mammalian species. Neuroscience 105: 7-17

Crosby EC. 1969. Comparative aspects of cerebellar morphology. In: Llinás R, ed, Neurobiology of Cerebellar Evolution and Development. Chicago, Illinois, USA: American Medical Association; 1942

Deacon TW. 2 002. The human brain. In: Jones S, Martin R, Pilbeam D, eds, The Cambridge Encyclopedia of Human Evolution. Cambridge, UK: Cambridge University Press; 115-121.

Dobbing J. 1981. The later development of the brain and its vulnerability. In: Davies JA, Dobbing J; eds, Scientific Foundations of Paediatrics, $2^{\text {nd }}$ ed.
London, UK: William Heinemann; 744-758.

Dover G. Anti Dawkins. 2000. In: Rose H, Rose S, eds, Alas, Poor Darwin, Arguments Against Evolutionary Psychology. London, UK: Jonathan Cape; $47-66$

Ebbeson SOE. 1976. Morphology of the spinal cord. In: Llinás R, Precht W, eds, Frog Neurobiology. Heidelberg, Germany: Springer; 679-706.

Fleagle JG. 2002. Primate locomotion and posture. In: Jones S, Martin R, Pilbeam D, eds, The Cambridge Encyclopedia of Human Evolution. Cambridge, UK: Cambridge University Press; 75-79.

Forssberg H. Ontogeny of human locomotor control. 1985. I. Infant stepping, supported locomotion and transition to independent locomotion. Exp Brain Res 57: 480-493.

Forssberg H, Dietz V. 1997. Neurobiology of normal and impaired locomotor development. In: Connolly KJ, Forssberg H, eds, Neurophysiology and Neuropsychology of Motor Development. London, UK: MacKeith Press; 78-100.

Geisler HC, Westerga J, Gramsbergen A. 1993. Development of posture in the rat. Acta Neurobiol Exp 53: 517-523.

Geisler HC, Westerga J, Gramsbergen A. 1996. The function of the long back muscles during postural development in the rat. Brain Behav Res 80: 211215.

Geisler HC, Van der Fits IBM, Gramsbergen A. 1997. The effects of early vestibular deprivation on the motor development in the rat. Brain Behav Res 86: 89-96.

Geisler HC, Gramsbergen A. 1998. Motor development after vestibular deprivation in rats. Neurosci Biobehav Rev 22: 565-569.

Geisler HC, Gramsbergen A. 1998. The EMG development of the longissimus and multifidus muscles after plugging the horizontal semicircular canals. J Vestib Res 8: 399-409.

Gould SJ. 2000. More things in heaven and earth. In: In: Rose H, Rose S, eds, Alas, Poor Darwin, Arguments Against Evolutionary Psychology. London, UK: Jonathan Cape; 85-105.

Gramsbergen A. 1998. Posture and locomotion in the rat: independent or interdependent development? Neurosci Biobehav Rev 22: 547-553.

Gramsbergen A, Van Eykern LA, Taekema HC, Geisler HC. The activation of back muscles during locomotion in the developing rat. Brain Res Dev Brain Res 112: 217-228. 
Grillner S. 1981. Control of locomotion in bipeds, tetrapods and fish. In: Brookhart JM, Mountcastle VB, eds, Handbook of Physiology Section I, The Nervous System, Volume II part 2. Motor Control. Bethesda Maryland, USA: American Physiology Society; 1179-123.

Grillner S, Wallén P, Brodin L, Lansner A 1991. Neuronal network generating locomotor behaviour in lamprey: circuitry, transmitters, membrane properties, and simulation. Ann Rev Neurosci 14: 169-199.

Hadders-Algra M, Brogren E, Forssberg H. 1996. Ontogeny of postural adjustments during sitting in infancy: variation, selection and modulation. $J$ Physiol (Lond) 493: 273-288

Henderson S, Morris J, Frith U. 1981. The motor deficit in Down's syndrome children: a problem of timing? J Child Pyschol Psychiatr 22: 233-245.

Holstege G. 1991. Descending motor pathways and the spinal motor system: limbic and non-limbic components. Prog Brain Res 87: 307-421

Jones EG, Schreyer DJ, Wise SP. 1982. Growth and maturation of the rat corticospinal tract. Prog Brain Res 57: 361-379.

Joosten EA, Gribnau AA, Dederen PJ. 1989. Postnatal development of the corticospinal tract in the rat. An ultrastructural anterograde HRP study. Anat Embryol 179: 449-456.

Kjaerulff O, Kiehn O. 1996. Distribution of networks generating and coordinating locomotor activity in the neonatal rat spinal cord in vitro: a lesion study. J Neurosci 16: 5777-5794.

Kuypers HG. 1982. A new look at the organization of the motor system. Prog Brain Res 57: 381-403.

Lakke E. 1997. The projections to the spinal cord of the rat during development: a timetable of descent. Adv Anat Embryol Cell Biol 135: 1-143.

Lawrence DG, Kuypers HG. 1968. The functional organization of the motor system in the monkey. I. The effects of bilateral pyramidal lesions. Brain 91: 1-14.

Leakey MG, Feibel CS, McDougall I, Walker A. 1995. New four-million-year-old hominid species from Kanapoi and Allia bay, Kenya. Nature 376: 565-571.

Martin R. 2002. Walking on two legs. In: Jones S, Martin R, Pilbeam D, eds, The Cambridge Encyclopedia of Human Evolution. Cambridge, UK: Cambridge University Press; 78.

Orlovsky GN. 1972. The effect of different descending systems on flexor and extensor activity during locomotion. Brain Res 40: 359-371.

Peterson BW, Pitts NG, Fukushima K. 1979. Reticulospinal connections with limb and axial motoneurones. Exp Brain Res 36: 1-20.

Porter R, Lemon R. 1993. Corticospinal function and voluntary movement. Monographs of the Physiological Society, vol 45. Oxford, UK; Clarendon Press; 1-428.

Prechtl HFR. 1984. Continuity and change in early neural development. In: Prechtl HFR, ed, Continuity of Neural Functions from Prenatal to Postnatal Life. Clinics in Developmental Medicine 94; Oxford, Blackwell Scientific Publishers Ltd; 1-15.

Reisinger E. 1926. Untersuchungen am Nervensystem der Bothrioplana semperi. Z Morphol Ökol Tiere; 5: 119-149.

Romer AS. 1969. Vertebrate history with special reference to factors related to cerebellar evolution. In: Llinás R, ed, Neurobiology of Cerebellar Evolution and Development. Chicago, Illinois, USA: American Medical Associaton; 1-18.

Romijn HJ, Hofman MA, Gramsbergen A. 1991. At what age is the developing cerebral cortex of the rat comparable to that of the full-term newborn human baby? Early Hum Dev 26: 61-67.

Shumway-Cook A, Woollacott M. 1985. Dynamics of postural control in the child with Down syndrome. Physical Ther 65: 1315-1322.

Stringer CB. Evolution of early humans In: Jones S, Martin R, Pilbeam D, eds, The Cambridge Encyclopedia of Human Evolution. Cambridge, UK: Cambridge University Press, 2002; 241-251.

Ten Donkelaar HJ. 1982. Organization of descending path-ways to the spinal cord in amphibians and reptiles. Organization of descending pathways to the spinal cord in amphibians and reptiles. Prog Brain Res 57: 25-67.

Van der Fits IBM, Otten E, Klip AWJ, Van Eykern LA, Hadders-Algra M. 1999. The development of postural adjustments during reaching in healthy infants aged 6-18 months: evidence for two transitions. Exp Brain Res 126: 517-528.

Vinay L, Bussieres N, Shupliakov O, Dubuc R, Grillner S. 1998. Anatomical study of spinobulbar neurones in lampreys. J Comp Neurol 397: 475-492.

Vinay L, Brocard F, Pflieger JF, Simeoni-Alias J, Clarac F. 2000. Perinatal development of lumbar moto-neurones and their inputs in the rat. Brain Res Bull 53: 635-647. 
Ward CV, Leakey MG, Walker A. 2001. The earliest known australopithecus, $A$. anamensis. J Human Evolut 41: 255-368.

Westerga J, Gramsbergen A. 1990. The development of locomotion in the rat. Dev Brain Res 57: 163-174.

Westerga J, Gramsbergen A. 1993 . Changes in the EMG of two major hindlimb muscles during locomotor development in the rat. Exp Brain Res 92: 479-488.

Westerga J, Gramsbergen A. 1994. Development of the EMG of the soleus muscle in the rat. Dev Brain Res 80: 233-243.

Whishaw IQ, O'Connor WT, Dunnett SB. 1986. The contributions of motor cortex, nigrostriatal dopamine and caudate-putamen to skilled fore-limb use in the rat. Brain 109: 805-843.

Whishaw IQ, Metz GA. 2002. Assessment of the pyramidal tract contribution to skilled movement in the rat: Absence of impairments or recovery mediated by the uncrossed pyramidal tract in the rat versus enduring deficits prodced by the crossed pyramidal tract. Behav Brain Res 134: 323-336

White TD, Suwa G, Asfaw B. 1994. Austraolopithecus ramidus, a new species of early hominid from Aramis, Ethiopia. Nature 371: 306-312.

Wood BA, Evolution of australopithecins In: Jones S, Martin R, Pilbeam D, eds, The Cambridge Encyclopedia of Human Evolution. Cambridge, UK: Cambridge University Press, 2002; 231-240. 

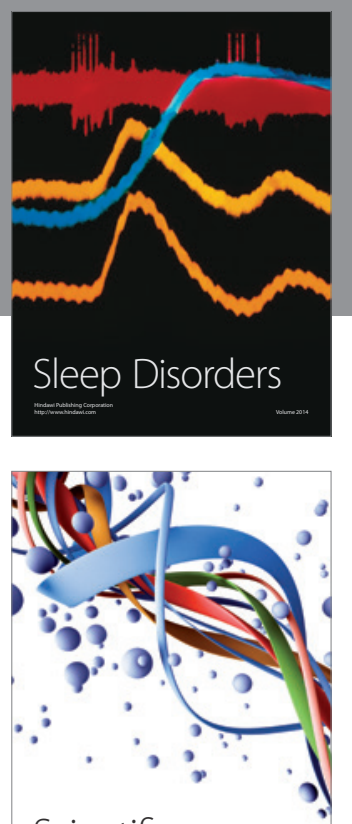

Scientifica
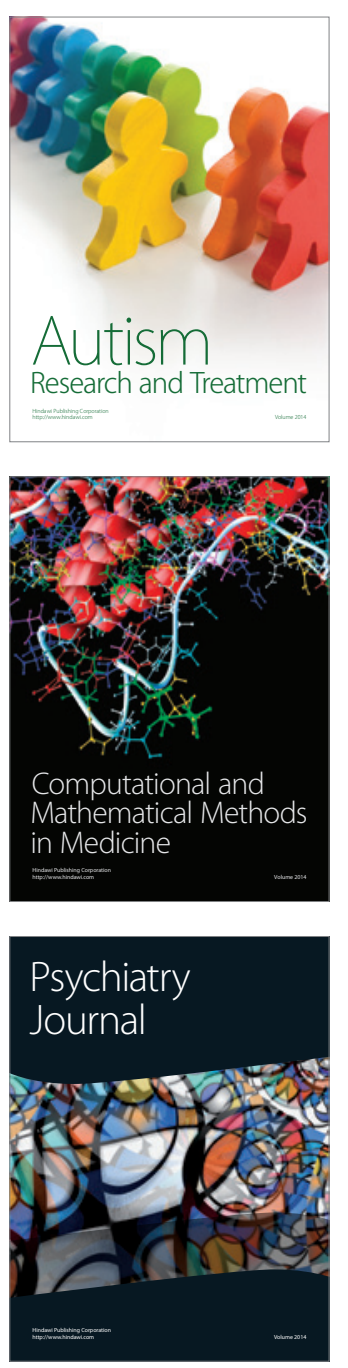
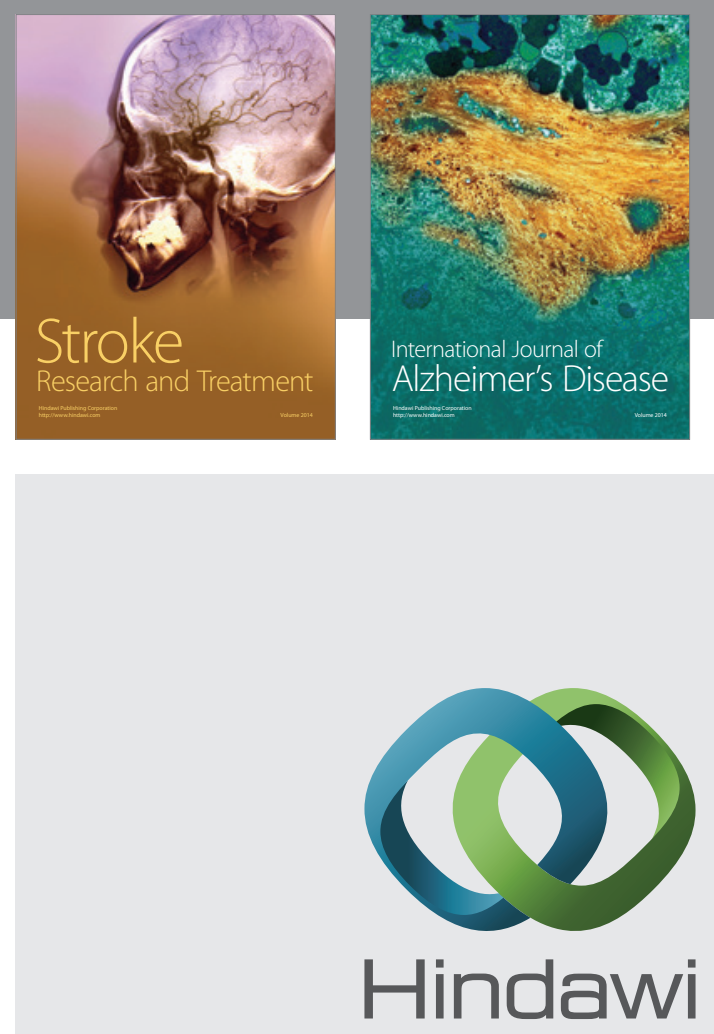

Submit your manuscripts at

http://www.hindawi.com
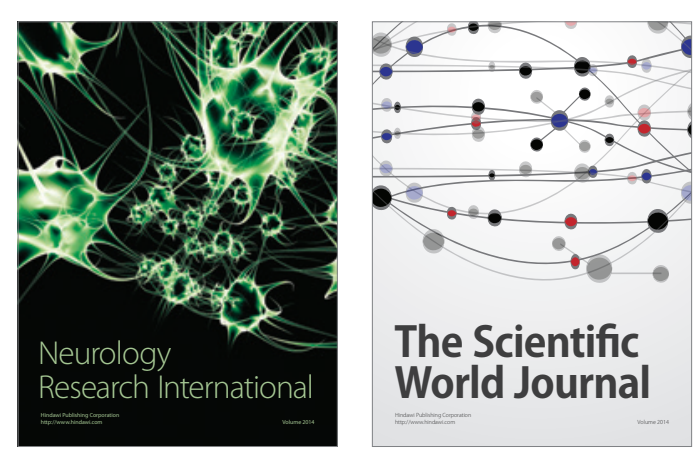

The Scientific World Journal

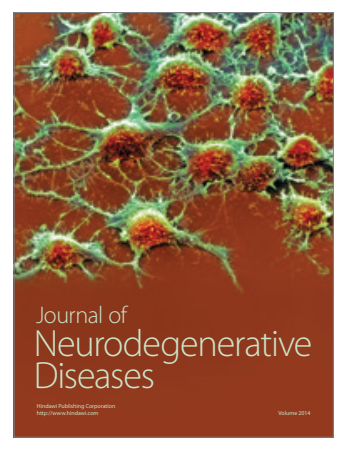

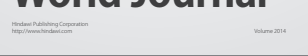

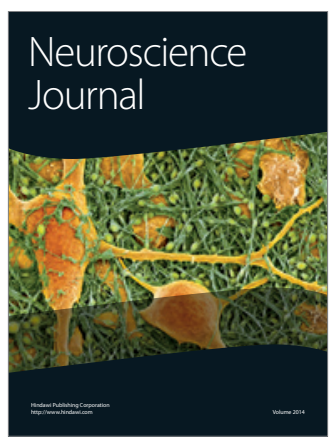

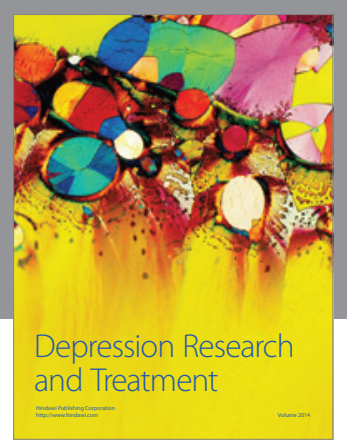
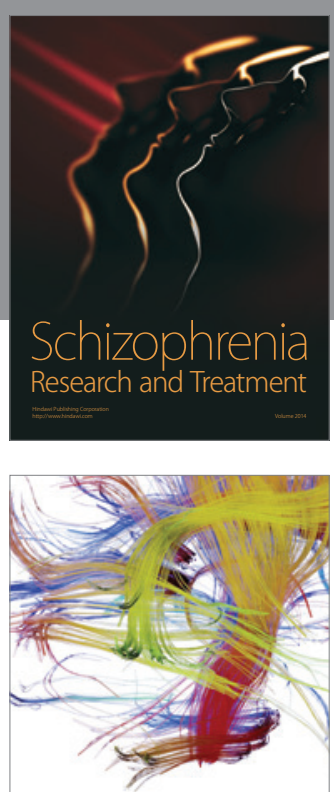

Brain Science

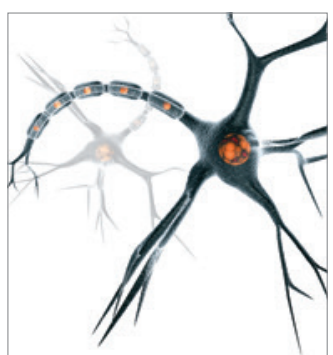

Neural Plasticity
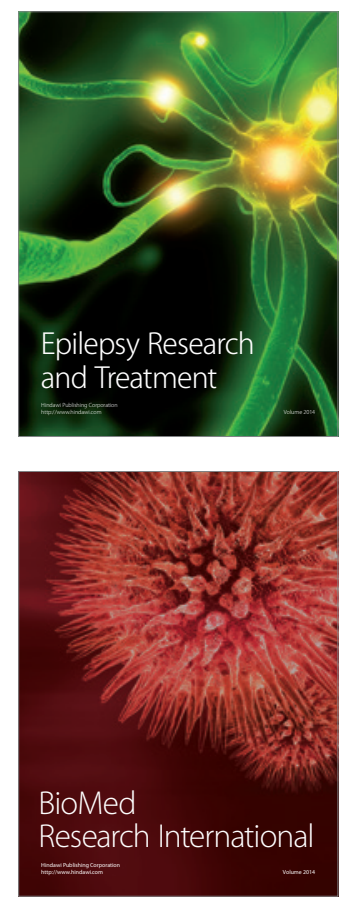

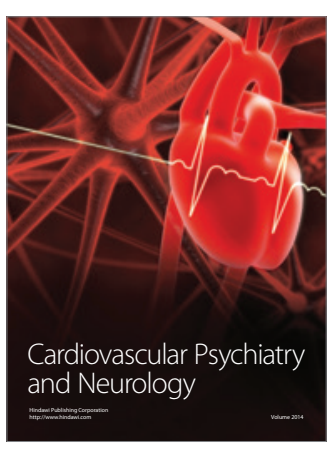

Parkinson's

Disease
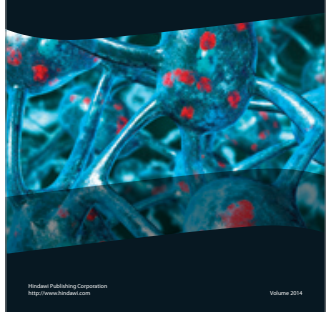